\title{
Influence of electric fields on the structure of chitosan edible coatings
}

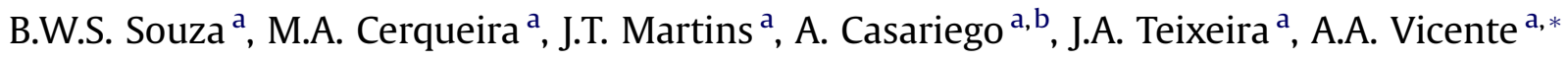 \\ ${ }^{a}$ IBB-Institute for Biotechnology and Bioengineering, Centre of Biological Engineering, Universidade do Minho, Campus de Gualtar, 4710-057 Braga, Portugal \\ ${ }^{\mathrm{b}}$ Instituto de Farmacia y Alimentos, Universidad de la Habana, La Habana, Cuba
}

\section{A R T I C L E I N F O}

\section{Article history:}

Received 25 June 2009

Accepted 19 October 2009

\section{Keywords:}

Edible coatings

Electric fields

Physical properties

Chitosan films

\begin{abstract}
A B S T R A C T
The aim of this work was to evaluate the effect of electric fields applied at different field strength values on mechanical and thermal properties of chitosan films/coatings (obtained from lobster of the Cuban coasts). XRD analyses indicated that electrically treated chitosan films exhibited a more ordered structure and a clearly higher crystallinity when compared with non-treated films, thus displaying significant effects on the value of the crystallinity index $(C I)$. SEM micrographs evidenced that the surface morphology of chitosan films was influenced by the electric field. In fact, the electric field treatment led to a structure with more regular layers as can be seen in the cross-sections of the films observed under SEM. The application of the electric field to chitosan film-forming solutions resulted in an increase of the tensile strength (c.a. 9\%) and elongation-at-break (c.a. 18\%) of the corresponding chitosan films. The reported results demonstrate that the application of an electric field to film-forming solutions of chitosan is an interesting instrument to taylor relevant properties of the films or coatings produced from them. (C) 2009 Elsevier Ltd. All rights reserved.
\end{abstract}

\section{Introduction}

Biodegradable and renewable materials are an important part of the effort to reduce the impact of food packaging in the environment. The development of edible films or coatings based on natural biopolymers (proteins, polysaccharides and their derivatives) provides a potential alternative to non-biodegradable packaging materials. Chitosan is a partially $\mathrm{N}$-deacetylated derivative of chitin, which is commonly found in shells of insects and crustaceans, as well as cell walls of some fungi, and is known as the second most abundant biopolymer in nature after cellulose (Singh et al., 2009). This natural polysaccharide shows wide application potentials in biology, medicine, food, electrochemistry, and membrane separation due to its attractive characteristics of low price, biocompatibility, hydrophilicity and chemical versatility (Liu, Chen, \& Chang, 2009). Chitosan has been widely used for the production of edible coatings and edible films (Casariego et al., 2008, 2009; Jeon, Kamil, \& Shahidi, 2002). Chitosan films are excellent oxygen and carbon dioxide barriers and have interesting antimicrobial properties (Casariego et al., 2009; Dutta, Tripathi, Mehrotra, \& Dutta, 2009). Compared with other polysaccharides, chitosan has been reported as a potential material for food packaging, especially integrating

\footnotetext{
* Corresponding author. Tel.: +351 253 604419; fax: +351 253678986.

E-mail address: avicente@deb.uminho.pt (A.A. Vicente).
}

edible films or coatings (Casariego et al., 2009; Souza et al., 2009; Suyatma, Tighzert, Copinet, \& Coma, 2005).

The cationic character of chitosan offers good opportunities to take advantage of electron interactions with numerous compounds during processing and to incorporate specific properties into the material (Lacroix \& Le Thien, 2005).

Ohmic heating is based on the passage of electrical current through a sample that has electrical resistance. The electrical energy is directly converted to heat and instant heating occurs, at a rate which depends on the intensity of the current passing through the material.

The use of electric fields in the food area has gained a new interest in recent years (Castro, Teixeira, Salengke, Sastry, \& Vicente, 2003; Castro, Teixeira, Salengke, Sastry, \& Vicente, 2004; Icier \& Ilicali, 2005).

The application of electric fields has also been an important instrument among researchers in the area of edible films and coatings, and there are works showing that the application of electric fields promotes a significant improvement of several properties (García, Pinotti, Martino, \& Zaritzky, 2009; Lei, Zhi, Xiujin, Takasuke, \& Zaigui, 2007; Souza et al., 2009).

Lei et al. (2007) reported advantages in the use of ohmic heating for the production of protein-lipid films, including the improvement of the yield, of the film formation rate and of the rehydration capacity of the films. García et al. (2009) analyzed the effect of applying an electrical field during drying on the microstructure of films formulated with different concentrations of chitosan and 
methyl-cellulose; those authors have shown that the electrical field treatment could be a good alternative to improve film flexibility and to increase water vapor barrier properties. Souza et al. (2009) applied a moderate electric field to chitosan film-forming solutions and showed that it affects the physical properties and structure of the films and coatings which are then reflected on their transport properties.

In this context, the objectives of the present work were to analyze the effect of applying a moderate electric field to filmforming solutions of chitosan, to evaluate the films' microstructure by SEM and X-ray diffraction analyses and to analyze their thermal and mechanical properties.

\section{Materials and methods}

\subsection{Coating materials}

The materials used to prepare the edible coating solutions were: chitosan (obtained in the Pharmaceutical Laboratories Mario Muñoz, Cuba) with a degree of deacetylation of $90 \%$ approximately, Tween 80 (Acros Organics, Belgium) as surfactant and lactic acid (90\%, Merck, Germany).

\subsection{Film formation}

The coating solutions were prepared dissolving the chitosan $(1.5 \% \mathrm{w} / \mathrm{v})$ in a $1 \%(\mathrm{v} / \mathrm{v})$ lactic acid solution with agitation using a magnetic stirrer during $2 \mathrm{~h}$ at room temperature $\left(20^{\circ} \mathrm{C}\right)$; subsequently, Tween 80 was added as a surfactant at a concentration of $0.1 \%(\mathrm{w} / \mathrm{w})$ (Casariego et al., 2008). After homogenizing, the chitosan solution was filtered to remove most of the undissolved impurities ( $<1 \%$ of the chitosan content). At the end of these treatments, a constant amount $(28 \mathrm{~mL})$ of chitosan solution was cast onto an $8 \mathrm{~cm}$ diameter glass plate in order to maintain the film thickness. The films were dried in an oven at $35^{\circ} \mathrm{C}$ during $8 \mathrm{~h}$. Dried films were peeled from the plate and cut in circles with $8 \mathrm{~cm}$ of diameter, approximately, for property testing.

\subsection{Device description}

A set of experiments was conducted to determine the effect of the application of a moderate electric field to chitosan solutions. The chitosan solution samples were treated in an ohmic heater using different field strengths (from 100 to $200 \mathrm{~V} \mathrm{~cm}^{-1}$ ) with a $2 \mathrm{~cm}$ gap between the electrodes, in all cases leading to an increase of temperature up to $60{ }^{\circ} \mathrm{C}$. The heater and data acquisition system used consisted of a cylindrical glass tube of $30 \mathrm{~cm}$ total length and $2.3 \mathrm{~cm}$ inside diameter; two Titanium electrodes with Teflon pressure caps were placed at each end of the tube (for details of the apparatus please refer to Castro et al. (2004) and Souza et al. (2009). Samples were heated using an alternating current source of $50 \mathrm{~Hz}$, with different field strengths. Temperatures were monitored using a type-K thermocouple, placed at the geometrical centre of the chamber though the available opening. A data-logger was employed to record continuously and simultaneously, current intensity, voltage and temperature. In order to measure voltage across and current through the samples, voltage and current transducers were used, respectively.

In order to collect data for the conventional heating, $30 \mathrm{~mL}$ Falcon tubes containing the chitosan solution samples were placed in a temperature controlled water bath. The thermal history of the samples, until temperature stabilization, was monitored by the introduction of a thermocouple in the geometrical center of the tubes, connected to the data acquisition system previously described; this treatment was used as control in order to discard the temperature effects and to evaluate only the effects of the electric field.

\subsection{Characterization of chitosan films}

\subsubsection{Conditioning}

All chitosan films used for permeability tests were conditioned in desiccators, at $20^{\circ} \mathrm{C}$ and $25 \% \mathrm{RH}$.

\subsubsection{Thickness}

Film thickness was measured with a hand-held digital micrometer (Mitutoyo, Japan) having a sensitivity of $0.001 \mathrm{~mm}$. Ten thickness measurements were taken on each testing sample in different randomly chosen points and the mean values were used to calculate films properties.

\subsubsection{Scanning electron microscopy (SEM)}

Scanning electron microscopy (SEM) analyses were performed with a scanning electron microscope (Nova NanoSEM 200, The Netherlands) with an accelerating voltage varying from 10 to $15 \mathrm{kV}$.

\subsubsection{X-ray diffraction and crystallinity}

$\mathrm{X}$-ray diffraction patterns of the films were analyzed between $2 \theta=4^{\circ}$ and $2 \theta=60^{\circ}$ with a step size $2 \theta=0.02^{\circ}$ in an X-ray diffraction instrument (Bruker D8 Discover, USA). The crystallinity index $(C I)$ was defined using the equation $C I=\left(I_{110}-I_{\mathrm{am}}\right) / I_{110}$ (Srinivasa, Ramesh, Kumar, \& Tharanathan, 2004), where $I_{110}$ is the maximum intensity $\left(2 \theta, 20^{\circ}\right)$ of the (110) lattice diffraction and $I_{\mathrm{am}}$ is the intensity of the amorphous diffraction $\left(2 \theta, 16^{\circ}\right)$.

\subsubsection{Mechanical properties: tensile strength (TS) and elongation- at-break (E)}

$T S$ and $E$ were measured with an Instron Universal Testing Machine (Model 4500, Instron Corporation, USA) following the guidelines of the ASTM Standard Method D 882-91. The initial grip separation was set at $30 \mathrm{~mm}$ and the crosshead speed was set at $5 \mathrm{~mm} / \mathrm{min}$. TS was expressed in MPa and calculated by dividing the maximum load $(\mathrm{N})$ by the initial cross-sectional area $\left(\mathrm{m}^{2}\right)$ of the specimen. $E$ was calculated as the ratio of the increased length to the initial length of a specimen $(30 \mathrm{~mm})$ and expressed as a percentage. $T S$ and $E$ tests were replicated five times for each type of film.

\subsubsection{Differential scanning calorimetry (DSC)}

DSC measurements were performed with a Shimadzu DSC-50 calorimeter (Shimadzu Corporation, Kyoto, Japan). About $10 \mathrm{mg}$ of the samples were placed in Aluminium DSC pans. The samples were heated from 25 to $350{ }^{\circ} \mathrm{C}$ at a heating rate of $10{ }^{\circ} \mathrm{C} \mathrm{min}-1$ under a Helium atmosphere.

\subsubsection{Statistical analyses}

Analysis of Variance (ANOVA) and linear regression were the main statistical tools used for data analysis. The Tukey test $(\alpha=0.05)$ was also used to determine the significance of differences between specific means (SigmaStat 3.1, 2004, Excel, 2003, USA).

\section{Results and discussion}

\subsection{X-ray diffraction}

Chitosan can exist in two distinct crystal forms, and many different patterns observed by X-ray diffraction represent different mixtures of the two forms. The use of higher molecular-weight $(M W)$ chitosan produces a less crystalline, smaller crystallite, rod 


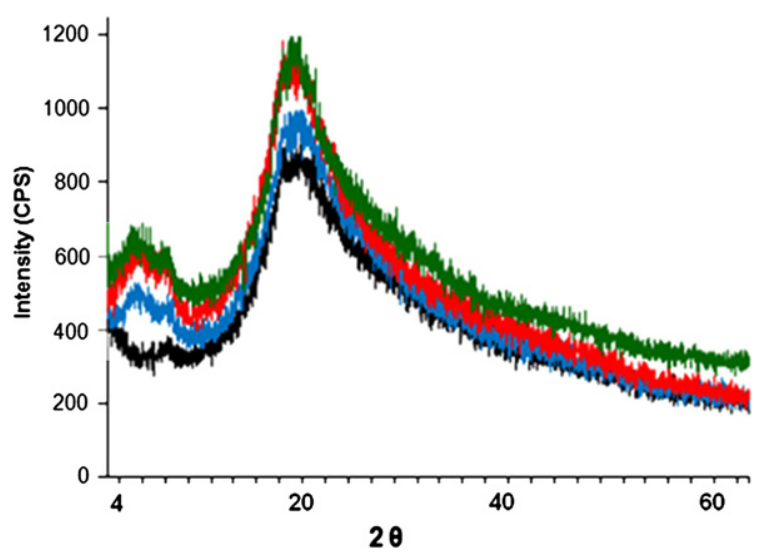

Fig. 1. X-ray diffraction patterns of chitosan films to (-) Control (-) Conventional heating (-), Electric fields $100 \mathrm{~V} \mathrm{~cm}^{-1}$ and (-) Electric fields $200 \mathrm{~V} \mathrm{~cm}^{-1}$.

structured film, while chitosan with lower $M W$ forms a more crystalline, and a larger crystallite spherulitic film. In summary, chitosan and chitosan-derived networks usually exhibit a semicrystalline structure due to the free-energy balance caused by hydrogen bonding formation (Costa-Júnior, Barbosa-Stancioli, Mansur, Vasconcelos, \& Mansur, 2009).

The X-ray diffraction patterns of all film samples are displayed in Fig. 1 . The diffraction peak around $19-20^{\circ}(2 \theta)$ observed for chitosan films in this work is in agreement with other published results
(Bangyekan, Aht-Ong, \& Srikulkit, 2006; Srinivasa et al., 2004; Ziani, Oses, Coma, \& Maté, 2008).

Fig. 1 shows that the crystallinity of the chitosan films increases gradually with the increase of the electric field strength. This indicates that, during the moderate electric field treatment, a structure with a different X-ray diffraction pattern was developed. This may be attributed to the fact that the chitosan chains with higher degree of deacetylation are more flexible. Flexible chains will facilitate the hydrogen bond formation and consequently crystallinity formation in the film. In addition, there was one other diffraction peak at around $8-10^{\circ}(2 \theta)$. Zhang, Ding, Ping, and Yu (2006) have shown that the reflection around $10^{\circ}(2 \theta)$ reflects the presence of a crystal form I and the strongest reflection at $2 \theta=20^{\circ}$ corresponds to a crystal form II.

Wan, Wu, Yu, and Wen (2006) demonstrated that the X-ray pattern of the chitosan membrane has two characteristic peaks located at $2 \theta$ of about $10.2^{\circ}$ and $20.2^{\circ}$. It is known that chitosan always contains bound water (5\%) even if it has been extensively dried. The incorporation of bound water molecules into the crystal lattice, commonly termed hydrated crystals, generally gives rise to a more dominated polymorph which can be normally detected by a broad crystalline peak in the corresponding X-ray pattern. Therefore, the crystalline peak centered at around $10^{\circ}$ is attributed to the hydrated crystalline structure of chitosan (Ogawa, Yui, \& Miya, 1992; Wan et al., 2006). Another peak registered near $20^{\circ}$ is reported to be the indication of the relatively regular crystal lattice (110) of chitosan (Wan et al., 2006; Yamamoto, Kawada, Yui, \& Ogawa, 1997).
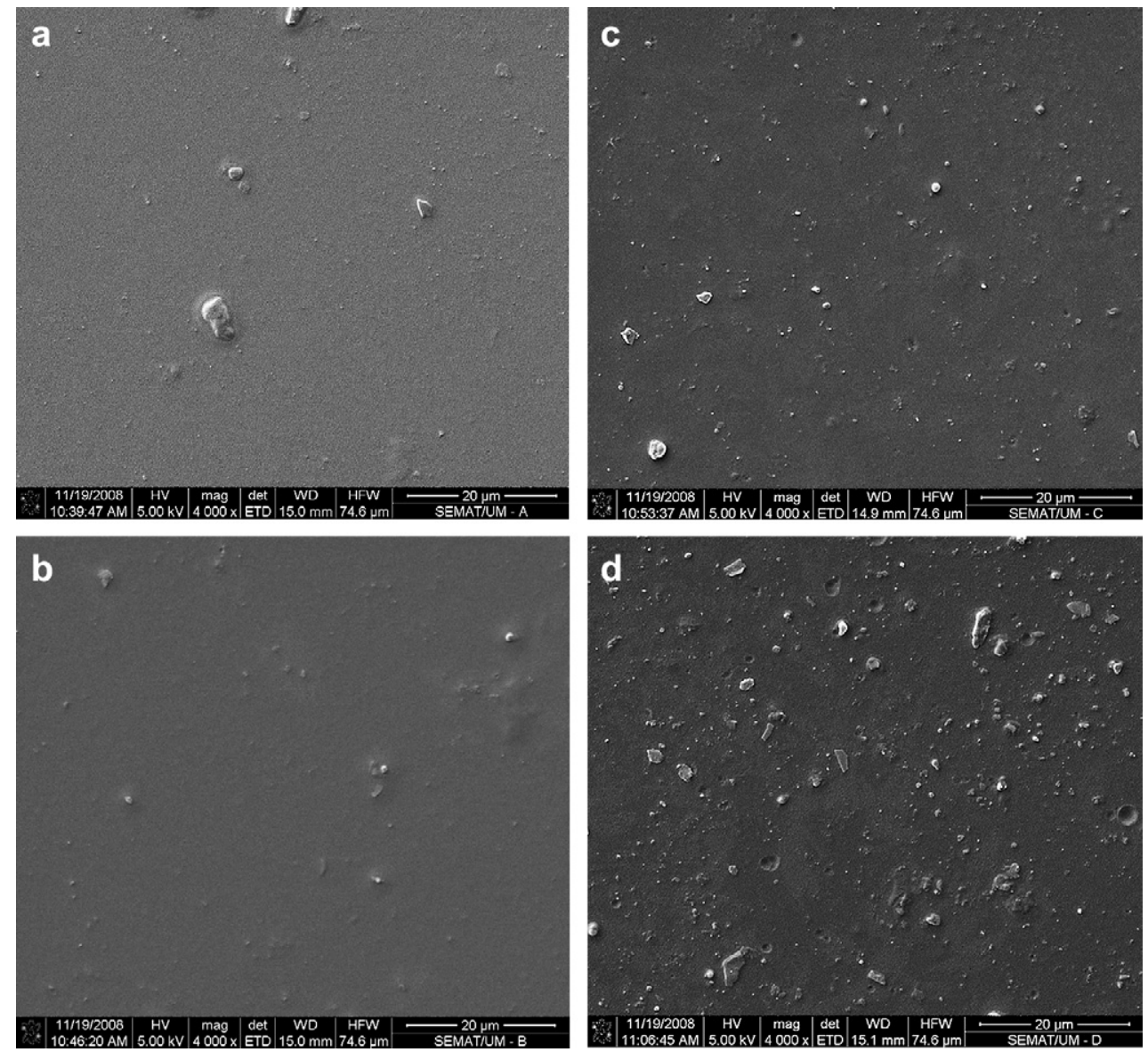

Fig. 2. SEM micrographs of chitosan films to (a) control, (b) conventional heating, (c) electric fields $100 \mathrm{~V} \mathrm{~cm}^{-1}$, (d) electric fields $200 \mathrm{~V} \mathrm{~cm}^{-1}$. 

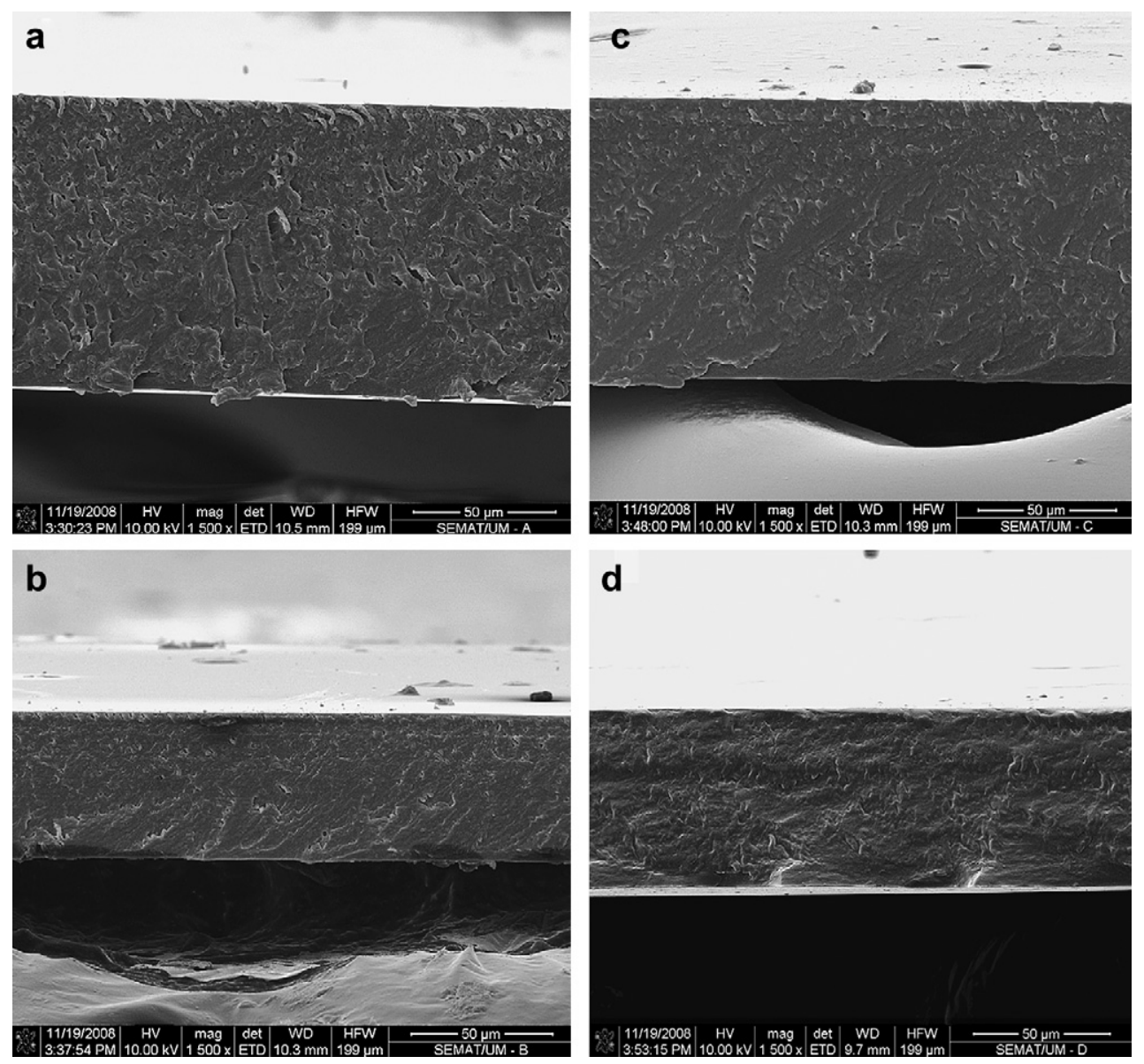

Fig. 3. Cross-section from chitosan films to (a) control, (b) conventional heating, (c) electric fields $100 \mathrm{~V} \mathrm{~cm}^{-1}$, (d) electric fields $200 \mathrm{~V} \mathrm{~cm}^{-1}$.

Results indicated that the application of a moderate electric field to the film-forming solutions had significant effects on the crystallinity index $(C I)$, which was higher for films treated with electrical fields. Balau, Lisa, Popa, Tura, and Melnig (2004) studied the X-ray diffractograms of chitosan films, an almost amorphous structure. They showed that films treated with an electric field of $E=20 \mathrm{kV} \mathrm{cm}^{-1}$, developed a crystalline structure, while the films to which no electric field was applied displayed a significantly lower proportion of crystalline material, showing that the electric field plays an important role in the crystallization process.

\subsection{Scanning electron microscopy (SEM)}

Several works involving the evaluation of edible films have used SEM when trying to correlate the properties of films with the same morphological structure (Chen, Kuo, \& Lai, 2009; García et al., 2009; Rhim, Hong, Park, \& Ng, 2006). Also in the present work the surface and cross-section morphology of chitosan films were analyzed using SEM.

The chemical characteristics of chitosan and its cationic character offer good opportunities to take advantage of electronic interactions with numerous compounds during processing and to incorporate specific properties into the material. When their filmforming solutions were submitted to an electric field, chitosan films have shown crystals in their structure, evidencing that there must have been morphological influences from that treatment. SEM analyses indicate that the electrical treatment significantly modified the structure of the films towards a more regular structure, which may presumably be reflected on the changes observed in the surface morphology of the film. The surface of the composite control films (Fig. 2a) looked more homogeneous than that of the treated films (Fig. 2c and d). Also, a structure with more regular layers was detected in the case of the film produced with the electrically treated film-forming solutions, as can be observed in the cross-section images of Fig. 3. Lei et al. (2007) mentioned that the major advantage of ohmic heating when preparing film-forming solutions is that the heat is dispersed uniformly throughout the whole liquid compared to water bath heating, concluding that the film formation rate was higher when ohmic heating was applied.

When studying gas permeation properties of chitosan films Souza et al. (2009) have shown that during the heating process heat was applied uniformly to the whole volume of the film, accelerating the collisions between molecules. This process can provide an improvement in the crystallinity of the chitosan film, thus increasing the material's resistance to gas permeation.

The development of films with a uniform and compact layer can be an important achievement towards the improvement of various film properties, such as their permeability to gases. The search for homogeneous structures thus becomes a target of the research involving edible films. In this perspective, the application of electric fields may provide an interesting solution for that problem and has gained importance in this area of research. García et al. (2009) showed that the surface morphologies of films were influenced by the preparation method, indicating that the application of an electric field during drying was an influencing factor.

\subsection{Mechanical properties}

Tensile strength (TS) and elongation-at-break $(E)$ are presented here to characterize the mechanical properties of the chitosan 

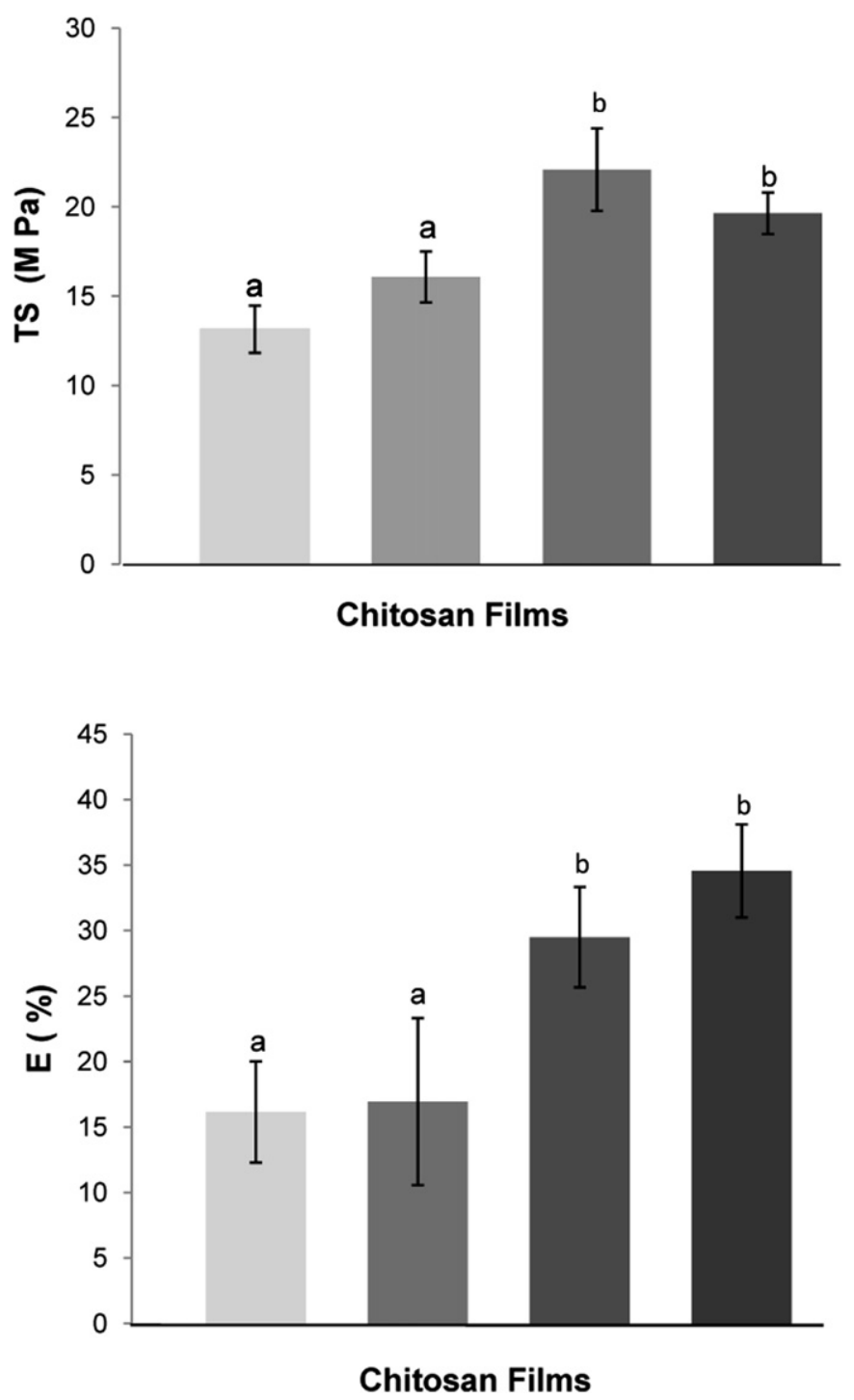

Fig. 4. Mechanical properties of chitosan films. $(\square)$ control $(\square)$ conventional heating

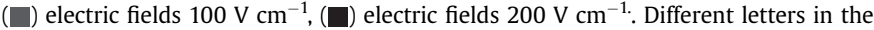
columns correspond to statistically different sample $(p<0.05)$.

films. TS are the maximum tension supported by the film until the moment it collapses. $E$ is a measure of the flexibility of the film and can be considered as a characteristic that defines the ability of the film deform in place before it collapses. These measurements are important once the mechanical properties of films or coatings depend on the filmogenic nature of the material used, which is directly related to its structural cohesion.

The measurement of the thickness is used to obtain the average thickness of the film, and this value is needed to calculate e.g. the film's mechanical properties. The thickness of films varied between $(43.00 \pm 1.37 \mu \mathrm{m}$ and $45.10 \pm 1.03 \mu \mathrm{m})$. No significant differences $(p>0.05)$ were detected between control and treated samples and therefore the thickness was presumably not the factor responsible for the differences obtained in the mechanical properties.

The results of the mechanical properties are shown in Fig. 4. The application of an electric field to chitosan film-forming solutions caused significant differences in TS (9\% increase) and $E(18 \%$ increase).

Several works reported that TS of chitosan films increased with increased molecular weight (Park, Marsh, \& Rhim, 2002) while other publications refer that the increase of the values of TS and $E$ for chitosan films is related with the deacetylation degree of the sample (Chen, Lin, \& Yang, 1994; Ziani et al., 2008). These authors mentioned that those results were due to the higher crystallinity of chitosan films. The polymer chain of chitosan with a higher degree of deacetylation was reported to be more mobile, and this increasing mobility was in turn related with an easier formation of inter-or intra-chain hydrogen bonds. This leads to a higher crystallinity degree that reduces the absorption of water molecules and produces an increase of TS (Ziani et al., 2008). In general, the crystallinity of films is related with increased intermolecular forces, thus increasing the rigidity and brittleness of the film (Cervera et al., 2004).

We have observed that when chitosan film-forming solutions were subjected to an electric field, the corresponding films of chitosan showed an increase in the degree of crystallinity of $15.3 \%$ (Table 1). These results confirmed the relationship between the application of electric field and the increase of crystallinity. Balau et al. (2004) showed that the electric field plays an important role in the crystallization process, and may also interfere in the water solubility of the films.

For films in general, mechanical orientation is a common practice to improve gas permeability, optical and mechanical properties; these properties can be modified by controlling chain polymer orientation, resulting on the formation of a more ordered structure, increasing the crystallinity, thus raising the maximum value of TS (Kirkwan \& Strawbridge, 2003). García et al. (2009), applying the electric field during the drying of films, have shown that electrically treated samples exhibited higher $E$ values, indicating that the electrical treatment allowed the alignment of the chains in the field direction, facilitating their stretching and thus increasing their flexibility.

\subsection{Differential scanning calorimetry and thermal stability}

Differential scanning calorimetry (DSC) is a technique which measures the difference between the energy supplied to a sample and the energy supplied to a reference material, when both are subjected to a controlled temperature programming. This is related with the change in enthalpy $(\Delta H)$ suffered by the sample. Changes in enthalpy are called first-order transitions (fusion, crystallization, vaporization, adsorption and solidification).

In the present work two endothermic peaks were detected for all films. The first endothermic peak that occurred over the temperature range of $78-94{ }^{\circ} \mathrm{C}$ was attributed to solvent evaporation (Lim \& Wan, 1995; Fernández et al., 2004; Xu, Ren, \& Milford, 2006; Casariego et al., 2009), while the peaks in the range of 100$190{ }^{\circ} \mathrm{C}$ were attributed to melting transition. The thermal properties of the tested chitosan films are summarized in Table 1. The films obtained with electrical field treatment have shown values of the melting temperature $\left(T_{\mathrm{m}}\right)$ and melting enthalpy $\left(\Delta H_{\mathrm{m}}\right)$ higher than the control. This could be attributed to crystallization of the chitosan films, indicating that the crystal forms and structure of chitosan were changed. Results show that the $T_{\mathrm{m}}$ and $\Delta H_{\mathrm{m}}$ increased from 122.1 to $136.3{ }^{\circ} \mathrm{C}$ and from 21.8 to $26.3 \mathrm{~J} / \mathrm{g}$, respectively, with

Table 1

Cristallinity, DSC data for the different treatments.

\begin{tabular}{llll}
\hline Treatments & Cristallinity index $(\%)$ & $T_{\mathrm{m}}\left({ }^{\circ}\right)$ & $\Delta H_{\mathrm{m}}(\mathrm{J} / \mathrm{g})$ \\
\hline Control & 39.1 & $122.1 \pm 4.50^{\mathrm{a}}$ & $21.8 \pm 0.46^{\mathrm{a}}$ \\
Conventional heating & 40.4 & $128.8 \pm 1.43^{\mathrm{a}}$ & $23.7 \pm 0.70^{\mathrm{ab}}$ \\
$100 \mathrm{~V} \mathrm{~cm}^{-1}$ & 52.2 & $133.1 \pm 1.19^{\mathrm{b}}$ & $24.8 \pm 1.56^{\mathrm{b}}$ \\
$200 \mathrm{~V} \mathrm{~cm}^{-1}$ & 54.4 & $136.3 \pm 2.28^{\mathrm{b}}$ & $26.3 \pm 1.85^{\mathrm{b}}$ \\
\hline
\end{tabular}

*Different letters in the same column correspond to statistically different samples $(p<0.05)$. 
the intensity of the electrical field treatment, suggesting that the degree of crystallinity of chitosan was increased, in line with the results from the XRD (Table 1 ).

\section{Conclusions}

The application of moderate electric fields to chitosan filmforming solutions had significant effects on the crystallinity index $(C I)$, as measured by DSC: those films treated with electrical fields featured higher $C I$ values. SEM results also evidenced that the surface of films presented morphological changes, resulting in a more regular structure. Changes were also noticed in terms of TS (increase of c.a. 9\%) and $E$ (increase of c.a. 18\%).

These results show that the application of electric fields to improve chitosan film-forming solutions may be an important instrument to taylor films' properties.

\section{Acknowledgements}

The author B.W.S. Souza is the recipient of a fellowship from the Coordenação de Aperfeiçoamento de Pessoal de Nível Superior (CAPES, Brazil), the authors M.A. Cerqueira and J. T. Martins are recipient of fellowships from the Fundação para a Ciência e Tecnologia (FCT, Portugal)(SFRH/BD/23897/2005 and RH/BD/32566/2006, respectively).

\section{References}

Balau, L., Lisa, G., Popa, M. I., Tura, V., \& Melnig, V. (2004). Physico-chemica properties of chitosan films. Central Europe Journal of Chemistry, 2(4), 638-647.

Bangyekan, C., Aht-Ong, D., \& Srikulkit, K. (2006). Preparation and properties evaluation of chitosan-coated cassava starch films. Carbohydrate Polymers, 63, 61-71.

Casariego, A., Souza, B. W. S., Cerqueira, M. A., Teixeira, J. A., Cruz, L., Díaz, R., et al. (2009). Chitosan/clay films' properties as affected by biopolymer and clay micro/nanoparticles' concentrations. Food Hydrocolloids, 23, 1895-1902.

Casariego, A., Souza, B. W. S., Vicente, A. A., Teixeira, J. A., Cruz, L., \& Díaz, R. (2008). Chitosan coating surface properties as affected by plasticizer, surfactant and polymer concentrations in relation to the surface properties of tomato and carrot. Food Hydrocolloids, 22, 1452-1459.

Castro, I., Teixeira, J. A., Salengke, S., Sastry, S. K., \& Vicente, A. A. (2003). The influence of field strength, sugar and solid content on electrical conductivity of strawberry products. Journal of Food Process Engineering, 26(1), 17-30.

Castro, I., Teixeira, J. A., Salengke, S., Sastry, S. K., \& Vicente, A. A. (2004). Ohmic heating of strawberry products: electrical conductivity measurements and ascorbic aci degradation kinetics. Innovative Food Science and Emerging Technologies, 5, 27-36.

Cervera, M. F., Heinämäki, J., Krogars, K., Jörgensen, A. C., Karjalainen, M. Colarte, A. I., et al. (2004). Solid-state and mechanical properties of aqueous chitosan-amylose starch films plasticized with polyols. American Association of Pharmaceutical Scientists PharmSciTech, 5(1). article 15.

Chen, C. H., Kuo, W. S., \& Lai, L. S. (2009). Effect of surfactants on water barrier and physical properties of tapioca starch/decolorized hsian-tsao leaf gum films. Food Hydrocolloids, 23, 714-721.

Chen, R. H., Lin, J. H., \& Yang, M. H. (1994). Relationships between the chain flexibilities of chitosan molecules and the physical properties of their casted films. Carbohydrate Polymers, 24, 41-46.

Costa-Júnior, E. S., Barbosa-Stancioli, E. F., Mansur, A. A. P., Vasconcelos, W. L., \& Mansur, H. S. (2009). Preparation and characterization of chitosan/poly(viny alcohol) chemically crosslinked blends for biomedical applications. Carbohydrate Polymers, 76, 472-481.

Dutta, P. K., Tripathi, S., Mehrotra, G. K., \& Dutta, J. (2009). Perspectives for chitosan based antimicrobial films in food applications. Food Chemistry 1173-1182.

Fernández, M., Heinämäki, J., Räsänen, M., Antikainen, O., Nieto, O. M., Iraizoz, A., et al. (2004). Determination of tackiness of chitosan film-coated pellets exploiting minimun fluidization velocity. International Journal of Pharmaceutics, 281, 119127

García, M. A., Pinotti, A., Martino, M., \& Zaritzky, N. (2009). Electrically treated composite films based on chitosan and methylcellulose blends. Food Hydrocolloids, 23, 722-728.

Icier, F., \& Ilicali, C. (2005). Temperature dependent electrical conductivities of fruit purees during ohmic heating. Food Research International, 38, 1135-1142.

Jeon, Y. J., Kamil, J. Y. V. A., \& Shahidi, F. (2002). Chitosan as an edible invisible film for quality preservation of herring and Atlantic cod. Journal of Agricultural and Food Chemistry, 50, 5167-5178.

Kirkwan, M., \& Strawbridge, J. (2003). Plastic in food packaging. In R. Coles, D. McDowell, \& M. Kirkwan (Eds.), Food packaging technology (pp. 174-240). Blakwell Publishing, CRC-Press.

Lacroix, M., \& Le Thien, C. (2005). Edible films and coatings from non-starch polysaccharide. In Jung H. Han (Ed.), Innovations in food packagings (pp. 338361). Amsterdam, The Netherlands: Elsevier.

Lei, L., Zhi, H., Xiujin, Z., Takasuke, I., \& Zaigui, L. (2007). Effects of different heating methods on the production of protein-lipid film. Journal of Food Engineering, 82, 292-297.

Lim, L. Y., \& Wan, S. C. (1995). Heat treatment of chitosan films. Drug Development and Industrial Pharmacy, 21, 839-846.

Liu, Y. L., Chen, W. H., \& Chang, Y. H. (2009). Preparation and properties of chitosan/ carbon nanotube nanocomposites using poly(styrene sulfonic acid)-modified CNTs. Carbohydrate Polymers, 76, 232-238.

Ogawa, K., Yui, T., \& Miya, M. (1992). Dependence on the preparation procedure of the polymorphism and crystallinity of chitosan membranes. Bioscience Biotechnology, and Biochemistry, 56, 858-862.

Park, S. Y., Marsh, K. S., \& Rhim, J. W. (2002). Characteristics of chitosan films as affected by the type of solvent acid. Journal of Food Science, 67, 194-197.

Rhim, J.-W., Hong, S.-I., Park, H.-W., \& Ng, P. K. W. (2006). Preparation and characterization of chitosan-based nanocomposite films with antimicrobial properties. Journal of Agricultural and Food Chemistry, 54, 5814-5822.

Singh, J., Dutta, P. K., Dutta, J., Hunt, A. J., Macquarrie, D. J., \& Clark, J. H. (2009). Preparation and properties of highly soluble chitosan-L-glutamic acid aerogel derivative. Carbohydrate Polymers, 76, 188-195.

Souza, B. W. S., Cerqueira, M. A., Casariego, A., Lima, A. M. P., Teixeira, J. A., \& Vicente, A. A. (2009). Effect of moderate electric fields in the permeation properties of chitosan coatings. Food Hydrocolloids, 23, 2110-2115.

Srinivasa, P. C., Ramesh, M. N., Kumar, K. R., \& Tharanathan, R. N. (2004). Properties of chitosan films prepared under different drying conditions. Journal of Food Engineering, 63, 79-85.

Suyatma, N. E., Tighzert, L., Copinet, A., \& Coma, V. (2005). Effects of hydrophilic plasticizers on mechanical, thermal and surface properties of chitosan films. Journal of Agricultural and Food Chemistry, 53, 3950-3957.

Wan, Y., Wu, H., Yu, A., \& Wen, D. (2006). Biodegradable polylactide/chitosan blend membranes. Biomacromolecules, 7, 1362-1372.

Xu, Y., Ren, X., \& Milford, A. (2006). Chitosan/clay nanocomposite film preparation and characterization. Journal of Applied Polymer Science, 99, 1684-1691.

Yamamoto, A., Kawada, J., Yui, T., \& Ogawa, K. (1997). Conformational behavior of chitosan in the acetate salt: an X-ray study. Bioscience Biotechnology and Biochemistry, 61, 1230-1232.

Zhang, C., Ding, Y., Ping, Q., \& Yu, L. L. (2006). Novel chitosan-derived nanomaterials and their micelle-forming properties. Journal of Agricultural and Food Chemistry, $54,8409-8416$.

Ziani, K., Oses, J., Coma, V., \& Maté, J. I. (2008). Effect of the presence of glycerol and Tween 20 on the chemical and physical properties of films based on chitosan with different degree of deacetylation. LWT - Food Science and Technology, 41, 2159-2165. 